\title{
PERITROPHIC MEMBRANES IN THE CARIDEA (CRUSTACEA DECAPODA)
}

\author{
By G. R. Forster \\ The Plymouth Laboratory
}

(Text-fig. I)

Observations on the faecal pellets of various shrimps and prawns were begun after the discovery in I949 of a thin transparent membrane surrounding the pellets of Spirontocaris pusiola (Krøyer). The presence of the membrane in the anterior part of the intestine showed that it could not be secreted by the hindgut, which is normally very short in the Caridea. Moore (1932) states that the faecal pellets of the Brachyura have a thin investment of mucus while those of the Caridea and lower groups have a thin clear outer layer. Subsequently a peritrophic membrane has been described in Daphnia (Chatton, I920) and in the barnacle Pollicipes (Batham, 1945). As the membrane found in Spirontocaris did not show the properties of mucus, a fuller investigation on its structure and function was made. A membrane has been found in all the Caridea so far examined. Palaemon serratus, the common prawn, has been used for many of the tests on account of its size and abundance.

\section{OCCURRENCE AND General ObSERVATIONS ON the MEMbrane}

A membrane has been observed around the faecal pellets of the following Caridea: Pandalus montagui Leach, Pandalina brevirostris Rathke, Hippolyte varians Leach, Spirontocaris cranchii (Leach), S. pusiola (Krøyer), Athanas nitescens Montagu, Processa canaliculata Leach, Palaemon serratus (Pennant), P. elegans Rathke (=Leander squilla (L.)), Crangon vulgaris L., and Philocheras trispinosus Hailstone.

In Palaemon, Hippolyte, Processa and Crangon a membrane has been observed in the intestine as well as around the faecal pellets. The membrane is not always easy to find if the faecal pellets are packed with material, but there are usually small indentations in the faecal strand where it is visible, appearing as a transparent section of the edge of the pellet. When Hippolyte is starved for a few days the pellets contain less faecal material and the membrane is clearly visible. Before the animal moults very long pellets are often produced with only slight traces of faecal matter, indicating that the stomach is being completely emptied. To starve Hippolyte, and probably any other small caridean, is not at all easy because of its coprophagous habit. The faecal pellets must be frequently removed, as Hippolyte and especially Palaemonetes 
can subsist, sometimes indefinitely, without any food by re-ingesting faecal pellets which contain large numbers of Protozoa.

With the larger pellets of Palaemon it has been possible to squeeze out the contents and observe the membrane in the form of a thin tube. But usually the slightest touch of a needle will cause the pellet to fragment. The membrane may also sometimes be obtained by itself if the pellets are washed in fresh water: the contents swell, and are slowly extruded from one end of the pellet, or else rupture the membrane. The process can be continued by washing first in dilute and then in more concentrated $\mathrm{NaOH}$ solution.

\section{The NATURE OF THE Membrane}

Chemical tests have been made on the pellets of Hippolyte and Palaemon to ascertain the composition of the membrane.

Effect of Acids and Alkalis. The membrane is insoluble in either weak or strong alkalis, and withstands boiling in concentrated $\mathrm{KOH}$ solution. This shows that it does not contain mucins or mucoids as these are soluble in dilute alkalis (Lloyd \& Shore, I938).

Concentrated $\mathrm{HCl}$ dissolves the membrane rapidly, but a dilute solution has little or no effect.

Chitin Test. As the results given above conform to the properties of chitin (Yonge, 1932), the standard van Wissenlingh test for chitin (Campbell, I929), critically discussed by Richards (I95I), was carried out. This has given positive results for the membranes surrounding the pellets of Hippolyte varians and Palaemon serratus, both with naturally extruded pellets and with others dissected out from the anterior part of the intestine. A few of the chitin tests have not been positive but this has probably been due to insufficient hydrolysis with $\mathrm{KOH}$. Owing to the small size and delicate nature of the test, pieces must not be allowed to boil, but heating for about $30 \mathrm{~min}$. at $150^{\circ} \mathrm{C}$. was found sufficient to obtain a good violet-red coloration with the iodine and sulphuric acid reagent. It was obviously difficult to be absolutely certain that the membrane itself, and not some of its contents, gave the positive reaction. On three occasions, however, pellets were obtained with clear sections of membrane that still gave the colour reaction satisfactorily. Moreover, when one pellet was treated with $3 \%$ acetic acid after boiling with $\mathrm{KOH}$, the membrane dissolved as chitosan should, but the contents of the pellet remained. No precipitate of chitosan sulphate was obtained, but this is hardly surprising in view of the minute quantity of material in the test.

\section{The Source of the Membrane}

Fig. IA shows the three regions of the gut. In numerous dissections a membrane has been found only in the intestine (mid-gut), and is assumed to be secreted by the epithelial cells. Sometimes the faecal thread and membrane projected a little way forward from the opening of the intestine, the anterior 
end being occasionally twisted or rolled up into a coil. This was doubtless brought about by mechanical disturbance during dissection and by antiperistaltic movements of the gut, as it was scarcely ever observed when the animals were first narcotized with urethane and the intestine separated from the stomach straightaway. Permanent sections were found unsatisfactory for
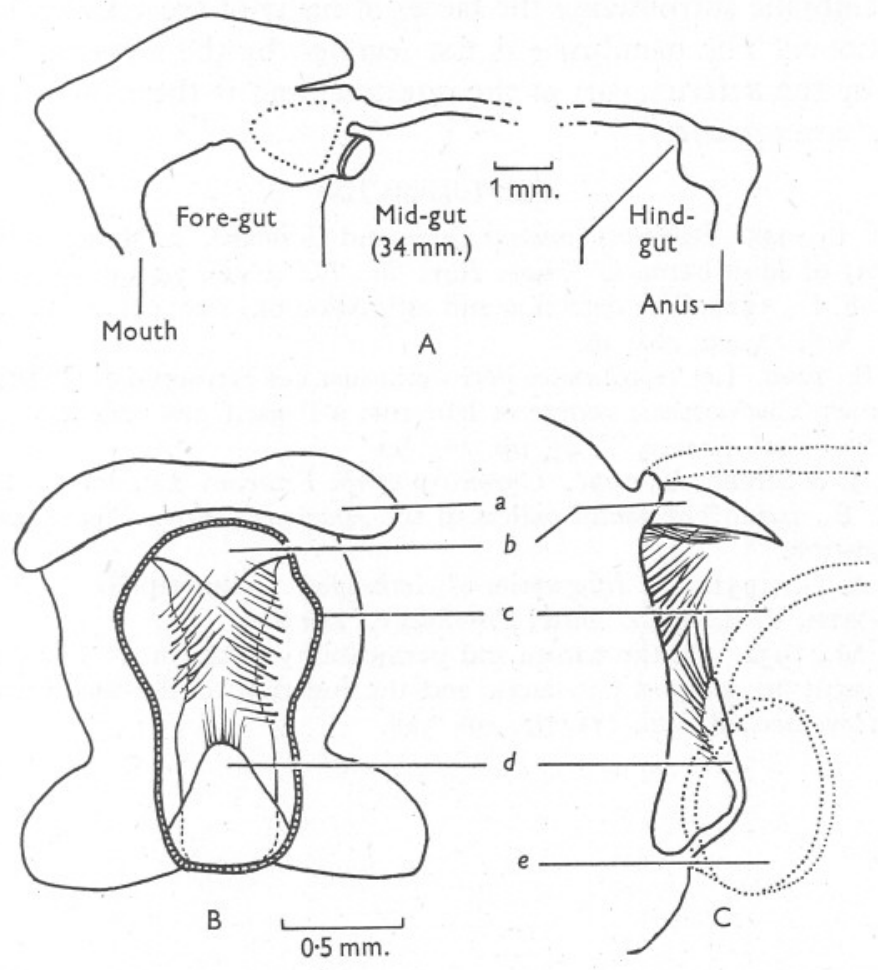

Fig. I. A, the regions of the alimentary canal of Palaemon serratus. The dotted area marks the position of the pyloric filter press. B, the posterior end of the pyloric filter press, looking forwards. C, side view of B. $a$, dorsal caecum; $b$, dorsal lip or valve; $c$, extreme anterior end of the intestinal wall; $d$, chitinous flap (? ventral valve); $e$, opening of the digestive gland duct.

observations on the membrane, which owing to its extreme fragility was nearly always damaged or so tightly pressed against the faecal material as to be indistinguishable from it. Fig. I (B, C) shows the junction of the mid-gut and fore-gut. Although at first it was thought that the membrane might be secreted around the dorsal lip, this would scarcely be possible in the presence of large numbers of setae, and no indication of it has been found.

As the membrane is produced in the mid-gut region and contains chitin it may be considered a true peritrophic membrane (Wigglesworth, I950). The 
function is probably to protect the epithelium lining the intestine from abrasive material, such as fragments of shells, sponge spicules, and setae which are often found in the stomach-contents of prawns.

\section{SUMMARY}

A thin membrane surrounding the faeces of many of the Caridea has proved to be chitinous. The membrane is not secreted by the fore-gut, but almost certainly by the anterior part of the intestine, and is therefore a peritrophic membrane sensu stricto.

\section{REFERENCES}

Batham, E. J., I945. Pollicipes spinosus Quoy and Gaimard. I. Notes on biology and anatomy of adult barnacle. Trans. Roy. Soc. N.Z., Vol. 74, pp. 359-74.

Campbell, F. L., I929. The detection and estimation of insect chitin. Ann. Ent. Soc. Amer., Vol. 22, pp. 40I-26.

Chatton, E., I920. Les membranes péritrophiques des Drosophiles (Diptères) et des Daphnies (Cladocères); genèse et leur rôle à l'égard des parasites intestinaux. Bull. Soc. Zool. France, T. 45, pp. 265-80.

Lloyd, D. J. \& Shore, A., I938. Chemistry of the Proteins. London.

Moore, H. B., I932. The faecal pellets of the Anomura. Proc. Roy. Edin., Vol. 52, pp. 296-308.

Richards, A. G., 1951. The Integument of Arthropods. Minneapolis.

Wigglesworth, V. B., I950. Insect Physiology. London.

YoNGE, C. M., I932. On the nature and permeability of chitin. I. The chitin lining the foregut of decapod Crustacea and the function of the tegumental glands. Proc. Roy. Soc., B, Vol. II I, pp. 298-328. 